\title{
Physico-Chemical Investigation of Endodontic Sealers Exposed to Simulated Intracanal Heat Application: Hydraulic Calcium Silicate-Based Sealers
}

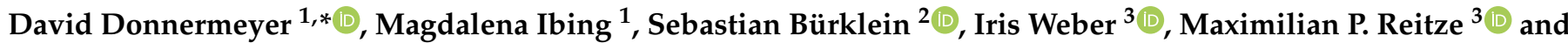 \\ Edgar Schäfer ${ }^{2}$ (D)
}

1 Department of Periodontology and Operative Dentistry, Westphalian Wilhelms-University, Albert-Schweitzer-Campus 1, Building W 30, 48149 Münster, Germany; magdalena.ibing@ukmuenster.de

2 Central Interdisciplinary Ambulance in the School of Dentistry, Albert-Schweitzer-Campus 1, Building W 30, 48149 Münster, Germany; sebastian.buerklein@ukmuenster.de (S.B.); eschaef@uni-muenster.de (E.S.)

3 Institute for Planetology, Westphalian Wilhelms-University, Wilhelm-Klemm-Str. 10, 48149 Münster, Germany; sonderm@uni-muenster.de (I.W.); maximilian.p-reitze@wwu.de (M.P.R.)

* Correspondence: david.donnermeyer@ukmuenster.de; Tel.: +49-251-8347064; Fax: +49-251-8347134

check for updates

Citation: Donnermeyer, D.; lbing, M.; Bürklein, S.; Weber, I.; Reitze, M.P.; Schäfer, E. Physico-Chemical Investigation of Endodontic Sealers Exposed to Simulated Intracanal Heat Application: Hydraulic Calcium Silicate-Based Sealers. Materials 2021, 14, 728. https://doi.org/10.3390/ ma14040728

Academic Editors: Marco Cicciù and Nikolaos Silikas

Received: 12 January 2021

Accepted: 27 January 2021

Published: 4 February 2021

Publisher's Note: MDPI stays neutral with regard to jurisdictional claims in published maps and institutional affiliations.

Copyright: (c) 2021 by the authors. Licensee MDPI, Basel, Switzerland. This article is an open access article distributed under the terms and conditions of the Creative Commons Attribution (CC BY) license (https:// creativecommons.org/licenses/by/ $4.0 /)$.

\begin{abstract}
The aim of this study was to gain information about the effect of thermal treatment of calcium silicate-based sealers. BioRoot RCS (BR), Total Fill BC Sealer (TFBC), and Total Fill BC Sealer HiFlow (TFHF) were exposed to thermal treatment at $37^{\circ} \mathrm{C}, 47^{\circ} \mathrm{C}, 57^{\circ} \mathrm{C}, 67^{\circ} \mathrm{C}, 77^{\circ} \mathrm{C}, 87^{\circ} \mathrm{C}$ and $97^{\circ} \mathrm{C}$ for $30 \mathrm{~s}$. Heat treatment at $97^{\circ} \mathrm{C}$ was performed for 60 and $180 \mathrm{~s}$ to simulate inappropriate application of warm obturation techniques. Thereafter, specimens were cooled to $37^{\circ} \mathrm{C}$ and physical properties (setting time/flow/film thickness according to ISO 6876) were evaluated. Chemical properties (Fourier-transform infrared spectroscopy) were assessed after incubation of the specimens in an incubator at $37^{\circ} \mathrm{C}$ and $100 \%$ humidity for 8 weeks. Statistical analysis of physical properties was performed using the Kruskal-Wallis-Test $(P=0.05)$. The setting time, flow, and film thickness of TFBC and TFHF were not relevantly influenced by thermal treatment. Setting time of BR decreased slightly when temperature of heat application increased from $37^{\circ} \mathrm{C}$ to $77^{\circ} \mathrm{C}(P<0.05)$. Further heat treatment of BR above $77^{\circ} \mathrm{C}$ led to an immediate setting. FT-IR spectroscopy did not reveal any chemical changes for either sealers. Thermal treatment did not lead to any substantial chemical changes at all temperature levels, while physical properties of BR were compromised by heating. TFBC and TFHF can be considered suitable for warm obturation techniques.
\end{abstract}

Keywords: BioRoot RCS; calcium silicate; calcium silicate-based sealer; intracanal heat application; warm vertical obturation; Total Fill BC Sealer; Total Fill BC Sealer HiFlow; Fourier-transform infrared spectroscopy; ISO 6876; root canal filling materials; root canal obturation

\section{Introduction}

Calcium silicate-based sealers were introduced to endodontics more than a decade ago [1]. In addition, other calcium silicate-based materials for direct pulp capping [2] and root end filling [3] have become standard in modern dentistry. Whilst calcium silicatebased sealers display a new material class incorporating beneficial properties from calcium silicate cements, these new sealers attempted to change a dogma of root canal obturation. Previously, a relatively high proportion of a core material such as gutta-percha and a small amount of a root canal sealer were the desired outcome of root canal filling. Calcium silicate-based sealers though were designed for cold obturation techniques, especially for single cone root canal filling [4]. Higher sealer proportions were no longer considered disadvantageous, as biological and antibacterial effects of calcium-silicate based sealers are thought to enhance the success of root canal treatment. Due to a low compression of the root canal filling material and sealer during single cone root canal filling, this technique is regarded as incapable of filling complex root canal systems [5]. In simpler 
root canal anatomies, it might allow sufficient root canal filling [6]. Warm root canal obturation techniques were invented to allow three-dimensional filling of complex root canal systems [5,7]. To fill canal irregularities and potentially lateral canals, gutta-percha is thermoplasticized inside or outside the root canal and inserted into the canal. This leads to a lower proportion of root canal sealer within the root canal filling. Still, the sealer is necessary to seal the root canal system at the root canal wall [8].

To allow the use of warm obturation techniques together with calcium silicate-based sealers, a new sealer-Total Fill BC Sealer HiFlow (TFHF; FKG Dentaire, La Chaux des Fonds, Switzerland) — was recently introduced [9]. It is labelled to fulfil all requirements for a sealer to be used with warm vertical root canal filling techniques. Previously, no calcium silicate-based sealer suitable for warm vertical compaction techniques was commercially available and warm obturation techniques were limited to other sealer types such as epoxy resin- or zinc oxide eugenol-based. These sealers were already proven to be stable when exposed to intracanal heat application [10]. Other calcium silicate-based sealers like Total Fill BC Sealer (TFBC; FKG Dentaire) or BioRoot RCS (BR; Septodont, St. Maur-des-Fossés, France) have recently been investigated regarding their behavior when exposed to heat application. Physical and chemical properties were investigated, during or shortly after the application of heat [11-15]. While the physical properties of TFHF were not negatively affected by heat, BR and TFBC were reported for increased viscosity [11]. Chemical changes were found in TFBC during the thermal treatment, but reported to remiss after the cooling process while BR was reported as having persisting chemical changes [12]. Shortly after setting, no alterations were reported for TFHF, TFBC, and BioRoot RCS after initial thermal treatment [11]. Though the setting reaction of calcium silicate-based materials is a process of several weeks [16], no data are, so far, available that address the long-term effect of thermal treatment on calcium silicate-based sealers. In addtion, the heat treatments in some previous studies were rather simple, as specimens were treated in ovens for a certain period at only a few temperature levels. Lately, a more decisive and clinically based thermal treatment was presented in closed containers with thermographic control inside the sealer specimen to follow the clinical situation at its best $[10,17]$.

The aim of the this laboratory study was to assess, under simulated clinical conditions, the effect of clinically orientated thermal treatment on selected physical properties immediately after heating and on the long-term chemical properties of calcium silicate-based sealers. The null hypothesis tested was that duration of heat application and range of temperature have no relevant impact on the physical (setting time, flow, film thickness) or chemical properties of the calcium silicate-based sealers BioRoot RCS, Total Fill BC Sealer, and Total Fill BC Sealer HiFlow.

\section{Materials and Methods}

Table 1 reveals the composition of the sealers as declared by the manufacturers. To allow comparison of the results, the method was applied in a similar manner to a previously published study on thermal effects on sealer [10].

\subsection{Heat Application on the Sealers}

On a glass plate, BR was mixed in strict accordance to the instructions provided by the manufacturer. TFBC and TFHF were dispensed directly from the syringe. Portions of $0.5 \mathrm{~mL}$ of each freshly mixed sealer were encapsulated into a $2 \mathrm{~mL}$ plastic tube (SafeLock Tubes, Eppendorf, Hamburg, Germany). Inside the samples, a K-type thermocouple (GHM Messtechnik, Regenstauf, Germany) was placed, and the samples were heated in a thermo-controlled water bath until the temperatures of $37^{\circ} \mathrm{C}, 47^{\circ} \mathrm{C}, 57^{\circ} \mathrm{C}, 67^{\circ} \mathrm{C}$, $77^{\circ} \mathrm{C}, 87^{\circ} \mathrm{C}$ and $97^{\circ} \mathrm{C}$ were achieved inside the samples (Figure 1). These temperatures were selected in accordance with recently published data [17], as the maximum intracanal temperatures reported were $19.1^{\circ} \mathrm{C}$ above body temperature. Furthermore, a wide range of temperatures was selected to assess the impact of overheating the sealers. The temperature of the sealer was checked using the mentioned K-Type thermocouple and the GSVmulti 
software (version 1.27, ME-Meßsysteme, Hennigsdorf, Germany) at a frequency of $50 \mathrm{~Hz}$ during the whole procedure to guarantee controlled warming of the sealers. Thereafter, all samples were retained for $30 \mathrm{~s}$ at the respective temperature and were then cooled to $37^{\circ} \mathrm{C}$ in a second water bath. In order to evaluate the influence of elongated heating, which may result when warm vertical compaction techniques are inappropriately implemented, samples were also heated to $97^{\circ} \mathrm{C}$ for 60 and $180 \mathrm{~s}$ [18]. After cooling the samples, they were exposed to testing of the physical properties or kept on glass plates in an incubator for 8 weeks at $37^{\circ} \mathrm{C}$ and $100 \%$ humidity until further evaluation of their chemical characteristics (Figure 1). The described procedure took about 3 min until the samples were analysed further.

Table 1. Composition of the sealers as provided by the manufacturers.

\begin{tabular}{ccc}
\hline & Component 1 & Component 2 \\
\hline BioRoot RCS & $\begin{array}{c}\text { Powder: Tricalcium silicate, } \\
\text { zirconium oxide, povidone }\end{array}$ & $\begin{array}{c}\text { Liquid: Aqueous solution of } \\
\text { calcium chloride and } \\
\text { polycarboxylate }\end{array}$ \\
\hline Total Fill BC Sealer & $\begin{array}{c}\text { Zirconium oxide, dicalcium } \\
\text { silicate, tricalcium silicate, } \\
\text { calcium phosphate monobasic, } \\
\text { calcium hydroxide, filler, } \\
\text { thickening agents }\end{array}$ \\
\hline Total Fill BC Sealer HiFlow & $\begin{array}{c}\text { Zirconium oxide, dicalcium } \\
\text { silicate, tricalcium silicate, } \\
\text { calcium hydroxide, filler }\end{array}$ \\
\hline
\end{tabular}

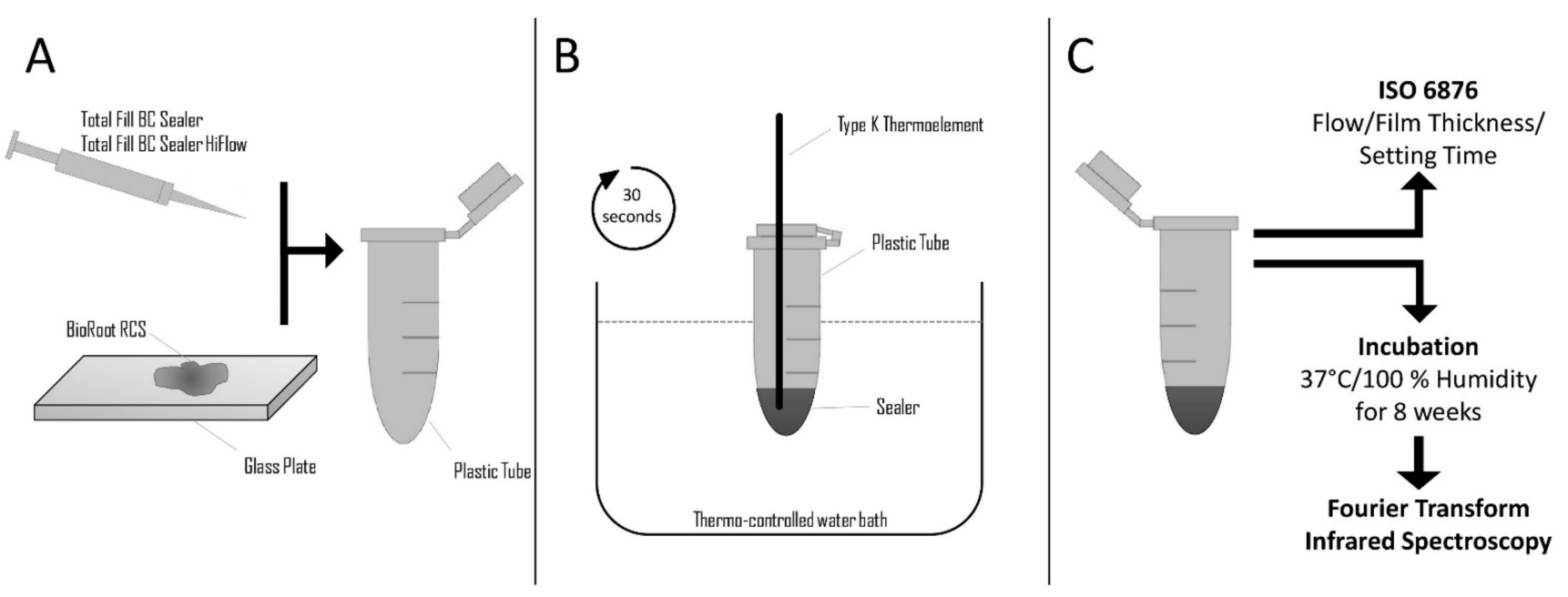

Figure 1. Schematic description of the experimental setup; (A): Total Fill BC Sealer and Total Fill BC Sealer HiFlow were dispensed directly to the vial. Mixing of BioRoot RCS and dispensing to plastic vial; (B): Thermal treatment of the Sealer; (C): Assessment of the physical and chemical characteristics of the sealers tested.

\subsection{Evaluation of Physical Characteristics}

\subsubsection{Setting Time}

According to ISO specification 6876:2012 (International Standard ISO 6876:2012), the sealers' setting time was evaluated [19]. The preheated sealer specimens were dispensed into plaster molds $(\mathrm{d}=10 \mathrm{~mm}, \mathrm{~h}=1 \mathrm{~mm})$ and transferred to an incubator at $37^{\circ} \mathrm{C}$ and $100 \%$ humidity. Using a stopwatch, the setting time of the material was measured. A cylindrical indenter with a flat end tip diameter of $2 \mathrm{~mm}$ and a mass of $100 \mathrm{~g}$ was used in accordance to 
ISO 6876. During the first hour after mixing, this procedure was repeated at 2-min intervals and thereafter at 30-min intervals. The setting point of the materials was defined as the point when the needle left no indentation on its surface. For each temperature level and each sealer, three iterations were performed and the mean was computed.

\subsubsection{Film Thickness}

The film thickness of the preheated samples was assessed in accordance to ISO specification 6876:2012, but due to the temporal process when preheating the sealers, minor adjustments were necessary. A small amount of each preheated sealer was situated on a glass plate (dimensions: $40 \mathrm{~mm} \times 40 \mathrm{~mm}$; thickness $5 \mathrm{~mm}$ ). Another glass plate with the same thickness, but a smaller surface area $\left(200 \mathrm{~mm}^{2}\right)$, was placed on top centrally. This second glass plate was loaded vertically for $10 \mathrm{~min}$ with $150 \mathrm{~N}$ using an universal testing machine (Lloyd LF Plus, Ametek, Berwin, PA, USA). Before each evaluation, the total thickness of the two assembled glass plates was determined using a digital micrometer and this was repeated after the testing procedure. For each group (temperature level and type of sealer), the measurements were performed in triplicate and the mean was computed.

\subsubsection{Flow}

Following thermal treatment, the sealers' flow was determined in accordance to ISO specification 6876:2012 with minor modifications. Because of the increased viscosity of the sealers at high temperatures, which was found in a preliminary study [10], the sealers were portioned by weight instead of volume. With the use of a precision scale and a graduated pipette, it was determined that $0.05 \mathrm{~mL}$ of sealer corresponded to $0.1265 \mathrm{~g}$ of Total Fill BC Sealer, $0.1276 \mathrm{~g}$ of Total Fill BC Sealer HiFlow, and $0.110 \mathrm{~g}$ of BioRoot RCS, respectively at $20^{\circ} \mathrm{C}$. All sealer portions were measured out by weight during the investigation. A certain amount of each specimen was placed on a glass plate with the same dimensions as described above. An identical second glass plate was placed on top centrally and the total mass was $120 \mathrm{~g}$. This assembly was kept for $10 \mathrm{~min}$. Using a digital caliper, the maximum and minimum diameters of the compressed sealer disc were measured. In the case the maximum and minimum diameters were within $1 \mathrm{~mm}$, the mean was computed. In the case of greater differences, the measurement was repeated. For each group (temperature level and type of sealer), the measurements were performed in triplicate and the mean was computed.

\subsection{Evaluation of Chemical Characteristics}

Fourier Transform Infrared Spectroscopy (FT-IR)

For FT-IR analysis of the preheated sealers, the set specimens were powdered using a mortar. A $0.002 \mathrm{~g}$ increment of sealer powder of each specimen was added to $0.200 \mathrm{~g}$ potassium bromide and pressed to a pill $(13 \mathrm{~mm}$ in diameter) with the help of a pellet die (Specac, Orpington, UK) and a manual laboratory compactor (Type PW 10, Paul-Otto Weber Laborpresstechnik, Remshalden, Germany). FT-IR was conducted using the Vertex 70v (Bruker, Billerica, MA, USA) with a mercury cadmium telluride (MCT) detector and the related software OPUS (Bruker). Background spectra of KBR were collected. Two tests (256 scans per test) with two different samples were performed for each temperature level to control the FT-IR analysis. As long as no difference between these two samples were evident, one result was selected for further graphic illustration and assessment.

\subsection{Statistical Analysis}

Data of the physical properties (setting time, film thickness and flow) were analyzed using the Kruskal-Wallis-Test at $P=0.05$, applying MedCalc (Version 19.5.6, MedCalc Software, Ostende, Belgium). Bonferroni adjustment was performed to allow post-hoc multiple comparisons. 


\section{Results}

Differences between the sealers regarding the time period required to attain the determined temperatures were not observed.

\subsection{Impact of Heat Application on Physical Characteristics}

3.1.1. Setting Time

The setting time of $\mathrm{BR}$ diminished slightly when temperature of heat application increased from $37^{\circ} \mathrm{C}$ to $77^{\circ} \mathrm{C}(P<0.05)$. Further heat treatment of BR above $77^{\circ} \mathrm{C}$ resulted in an immediate setting of the sealer (Table 2).

Table 2. Physical properties in accordance with ISO 6876:2012 of BioRoot RCS (means and standard deviations (SD)) after thermal treatment. Statistical analysis of setting time, film thickness and flow for BioRoot RCS was performed by Kruskal-Wallis-Test $(P=0.05)$.

\begin{tabular}{|c|c|c|c|c|c|c|c|c|c|c|}
\hline & \multirow{2}{*}{$\begin{array}{c}\text { Group } \\
\text { Number }\end{array}$} & \multicolumn{3}{|c|}{ Setting Time (min) } & \multicolumn{3}{|c|}{ Film Thickness $(\mu \mathrm{m})$} & \multicolumn{3}{|c|}{ Flow (mm) } \\
\hline & & Mean & SD & $\begin{array}{l}\text { Different } \\
\text { from Group } \\
\text { Number }\end{array}$ & Mean & SD & $\begin{array}{l}\text { Different } \\
\text { from Group } \\
\text { Number }\end{array}$ & Mean & SD & $\begin{array}{l}\text { Different } \\
\text { from Group } \\
\text { Number }\end{array}$ \\
\hline $37^{\circ}(30 \mathrm{~s})$ & 1 & 63.3 & 4.2 & 3 & 7.7 & 0.00 & - & 20.9 & 2.1 & - \\
\hline $47^{\circ}(30 \mathrm{~s})$ & 2 & 67.3 & 2.1 & $3,4,5$ & 7.8 & 0.04 & - & 20.7 & 3.1 & - \\
\hline $57^{\circ}(30 \mathrm{~s})$ & 3 & 52.3 & 1.5 & $1,2,4,5$ & 7.7 & 0.01 & - & 21.7 & 1.4 & - \\
\hline $67^{\circ}(30 \mathrm{~s})$ & 4 & 60.0 & 1.7 & 2,3 & 7.7 & 0.01 & - & 21.8 & 1.9 & - \\
\hline $77^{\circ}(30 \mathrm{~s})$ & 5 & 58.3 & 4.0 & 2,3 & 7.7 & 0.01 & - & 23.0 & 2.0 & - \\
\hline $87^{\circ}(30 \mathrm{~s})$ & 6 & * & & * & * & & * & * & & * \\
\hline $97^{\circ}(30 \mathrm{~s})$ & 7 & * & & * & $*$ & & * & * & & * \\
\hline $97^{\circ}(60 \mathrm{~s})$ & 8 & $*$ & & * & * & & * & * & & * \\
\hline $97^{\circ}(180 \mathrm{~s})$ & 9 & * & & * & * & & * & * & & * \\
\hline$P$-value & & & & $P=0.025057$ & & & $P=0.973880$ & & & $P=0.609215$ \\
\hline
\end{tabular}

${ }^{*}$ Material fully set after the heat treatment process: Setting time tending towards zero, film thickness, and flow test not applicable.

The setting time of TFBC varied at about 17 to $19 \mathrm{~h}$, whereas setting time of TFHF was approximately $22 \mathrm{~h}$ at all temperatures. Setting time of TFBC (Table 3) and TFHF (Table 4) did not reach a clinically relevant minimum threshold. 
Table 3. Physical properties in accordance with ISO 6876:2012 of Total Fill BC Sealer (means and standard deviations (SD)) after thermal treatment. Statistical analysis of setting time, film thickness and flow for Total Fill BC Sealer was performed by Kruskal-Wallis-Test $(P=0.05)$.

\begin{tabular}{|c|c|c|c|c|c|c|c|c|c|c|}
\hline & \multirow[t]{2}{*}{$\begin{array}{l}\text { Group } \\
\text { Number }\end{array}$} & \multicolumn{3}{|c|}{ Setting Time (h) } & \multicolumn{3}{|c|}{ Film Thickness ( $\mu \mathrm{m})$} & \multicolumn{3}{|c|}{ Flow (mm) } \\
\hline & & Mean & SD & $\begin{array}{l}\text { Different } \\
\text { from Group } \\
\text { Number }\end{array}$ & Mean & SD & $\begin{array}{l}\text { Different } \\
\text { from Group } \\
\text { Number }\end{array}$ & Mean & SD & $\begin{array}{l}\text { Different } \\
\text { from Group } \\
\text { Number }\end{array}$ \\
\hline $37^{\circ}(30 \mathrm{~s})$ & 1 & Mean & SD & $2,4,5,9$ & 7.7 & 0.00 & $4,6,4,9$ & 24.9 & 0.7 & - \\
\hline $47^{\circ}(30 \mathrm{~s})$ & 2 & 19.3 & 1.4 & $1,6,7$ & 7.7 & 0.00 & $6,7,9$ & 25.0 & 0.7 & - \\
\hline $57^{\circ}(30 \mathrm{~s})$ & 3 & 17.5 & 0.5 & 4 & 7.7 & 0.00 & 7,9 & 24.6 & 0.3 & - \\
\hline $67^{\circ}(30 \mathrm{~s})$ & 4 & 18.1 & 0.1 & $1,3,6,7,8$ & 7.7 & 0.01 & 1,8 & 24.7 & 0.8 & - \\
\hline $77^{\circ}(30 \mathrm{~s})$ & 5 & 17.1 & 0.4 & $1,6,7$ & 7.7 & 0.00 & $6,7,9$ & 25.4 & 1.1 & - \\
\hline $87^{\circ}(30 \mathrm{~s})$ & 6 & 17.5 & 0.3 & $2,4,5,8,9$ & 7.7 & 0.01 & $1,2,5,8$ & 23.9 & 0.5 & - \\
\hline $97^{\circ}(30 \mathrm{~s})$ & 7 & 19.2 & 0.4 & $2,4,5,9$ & 7.7 & 0.01 & $1,2,3,5,8$ & 28.0 & 2.0 & - \\
\hline $97^{\circ}(60 \mathrm{~s})$ & 8 & 19.1 & 0.6 & 4,6 & 7.7 & 0.00 & $4,6,7,9$ & 24.8 & 1.5 & - \\
\hline $97^{\circ}(180 \mathrm{~s})$ & 9 & 18.1 & 0.4 & $1,6,7$ & 7.7 & 0.00 & $1,2,3,5,8$ & 26.2 & 2.8 & - \\
\hline$P$-value & & & & $P=0.020231$ & & & $P=0.0187664$ & & & $P=0.213943$ \\
\hline
\end{tabular}

Table 4. Physical properties in accordance with ISO 6876:2012 of Total Fill BC Sealer HiFlow (means and standard deviations (SD)) after thermal treatment. Statistical analysis of setting time, film thickness and flow for Total Fill BC Sealer HiFlow was performed by Kruskal-Wallis-Test $(P=0.05)$.

\begin{tabular}{ccccccccccc}
\hline & $\begin{array}{c}\text { Group } \\
\text { Number }\end{array}$ & & \multicolumn{2}{c}{ Setting Time (h) } & \multicolumn{2}{c}{ Film Thickness ( $\mu$ m) } & Flow (mm) \\
\hline & & Mean & SD & $\begin{array}{c}\text { Different } \\
\text { from Group } \\
\text { Number: }\end{array}$ & Mean & SD & $\begin{array}{c}\text { Different } \\
\text { from Group } \\
\text { Number: }\end{array}$ & $\begin{array}{c}\text { Mean } \\
\text { SD } \\
\text { from Group } \\
\text { Number: }\end{array}$ \\
\hline $37^{\circ}(30 \mathrm{~s})$ & 1 & 23.0 & 0.0 & $6,7,8,9$ & 7.8 & 0.07 & - & 29.0 & 1.1 & 5,8 \\
\hline $47^{\circ}(30 \mathrm{~s})$ & 2 & 23.2 & 0.2 & $4,5,6,7,8,9$ & 7.7 & 0.01 & - & 30.7 & 1.7 & $4,5,6,8,9$ \\
\hline $57^{\circ}(30 \mathrm{~s})$ & 3 & 23.0 & 0.9 & $6,7,8,9$ & 7.7 & 0.01 & - & 30.7 & 0.8 & $4,5,6,8,9$ \\
\hline $67^{\circ}(30 \mathrm{~s})$ & 4 & 22.5 & 0.7 & $2,8,9$ & 7.7 & 0.00 & - & 28.4 & 1.0 & $2,3,8$ \\
\hline $77^{\circ}(30 \mathrm{~s})$ & 5 & 22.3 & 0.5 & 2,8 & 7.7 & 0.01 & - & 27.7 & 0.2 & $1,2,3,7$ \\
\hline $87^{\circ}(30 \mathrm{~s})$ & 6 & 22.2 & 0.1 & $1,2,3,8$ & 7.7 & 0.00 & - & 28.5 & 0.3 & $2,3,8$ \\
\hline $97^{\circ}(30 \mathrm{~s})$ & 7 & 22.0 & 0.4 & $1,2,38$ & 7.7 & 0.01 & - & 29.1 & 1.3 \\
\hline $97^{\circ}(60 \mathrm{~s})$ & 8 & 20.0 & 0.6 & $1,2,3,4,5,6,7$ & 7.7 & 0.01 & - & 26.7 & 0.2 & $1,2,3,4,6,7$ \\
\hline $97^{\circ}(180 \mathrm{~s})$ & 9 & 21.6 & 0.1 & $1,2,3,4$ & 7.7 & 0.00 & - & 28.1 & 1.7 \\
\hline$P$-value & & & & $P=0.0111865$ & & & $P=0.204195$ & 2,3 \\
\hline
\end{tabular}

\subsubsection{Film Thickness}

The film thickness of BR varied constantly at approximately $8 \mu \mathrm{m}$ at temperatures of $37^{\circ} \mathrm{C}$ to $77^{\circ} \mathrm{C}$. Further heat treatment of BR above $77^{\circ} \mathrm{C}$ caused an immediate setting of the material and it was impossible to measure the film thickness (Table 2).

Film thickness of TFBC and TFHF varied at approximately $8 \mu \mathrm{m}$ and was in accordance with the ISO 6876:2012 standard at all temperatures (Tables 3 and 4). 


\subsubsection{Flow}

The flow rates of TFBC and TFHF were above $17 \mathrm{~mm}$ as required by the ISO 6876:2012 specification at all temperatures tested (Tables 3 and 4). In addition, the flow rates of BR were within these limitations up to a temperature level of $77^{\circ} \mathrm{C}$ (Table 2). Further heat treatment of BR caused an immediate setting of the sealer, and it was not possible to assess the flow rate.

Results of the statistical analysis are summarized in Tables $2-4$. No statistically significant differences occurred for film thickness of BR and TFHF as well as for flow of TFBC. Though statistically significant differences were found for setting time and partly for flow and film thickness, no pattern corresponding with the thermal treatment could be observed.

\subsection{Impact of Heat Application on Chemical Characteristics}

FT-IR spectroscopy revealed that independent of temperatures used and heating times chemical alterations of the sealers did not result, as no differences in the spectroscopic plots resulted after thermal treatment (Figures 2-4). TFBC and TFHF revealed similar spectra with differences in the intensity of absorption.

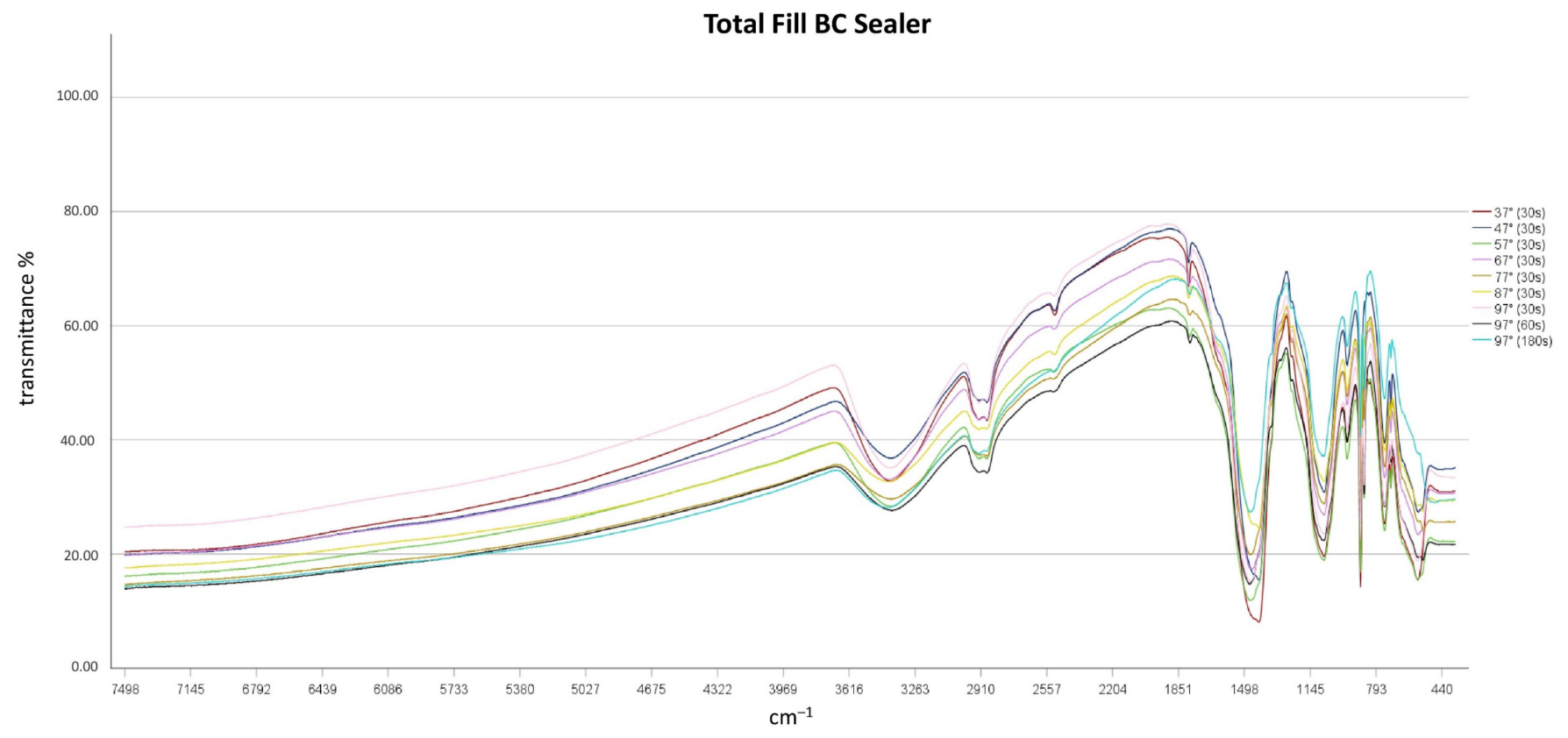

Figure 2. FT-IR spectroscopic plots of Total Fill BC Sealer.

A broad absorption band at $3400 \mathrm{~cm}^{-1}$ and a peak at $1650 \mathrm{~cm}^{-1}$ was detected in all sealers and at all temperature levels, indicating the presence of water in the specimens [13]. No characteristic $\mathrm{Ca}(\mathrm{OH})_{2}$ bands $\left(\mathrm{O}-\mathrm{H}\right.$ stretch at $\left.3646 \mathrm{~cm}^{-1}\right)$ were detected in TFHF and TFBC, while a small peak occurred in BR samples in this region [20]. Characteristic bands of carbonates were detected at 878 and from 1400 to $1500 \mathrm{~cm}^{-1}$ in all specimens [21,22]. Absorption intensities from 970 to $1000 \mathrm{~cm}^{-1}$ were observed in all specimens, indicating the formation of calcium silicate hydrate [21]. Two peaks were observed in TFBC and TFHF at $2874 \mathrm{~cm}^{-1}$ and $2923 \mathrm{~cm}^{-1}$, which were assigned to the symmetric stretching of $-\mathrm{CH}_{3}$ and $\mathrm{C}-\mathrm{H}$-stretching of $-\mathrm{CH}_{2-}^{-}$, respectively [23,24]. No such bands were observed in BR specimens. 


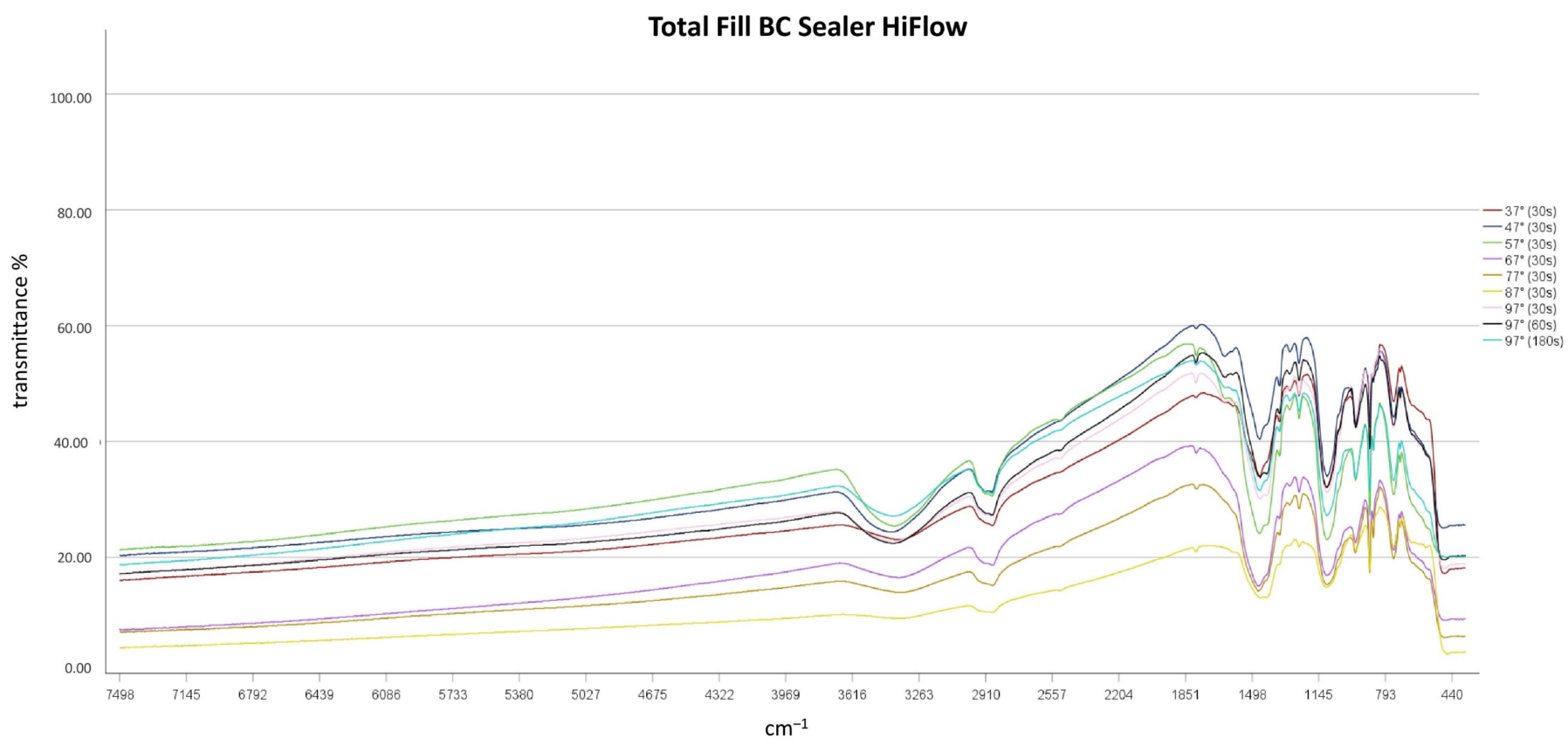

Figure 3. FT-IR spectroscopic plots of Total Fill BC Sealer HiFlow.

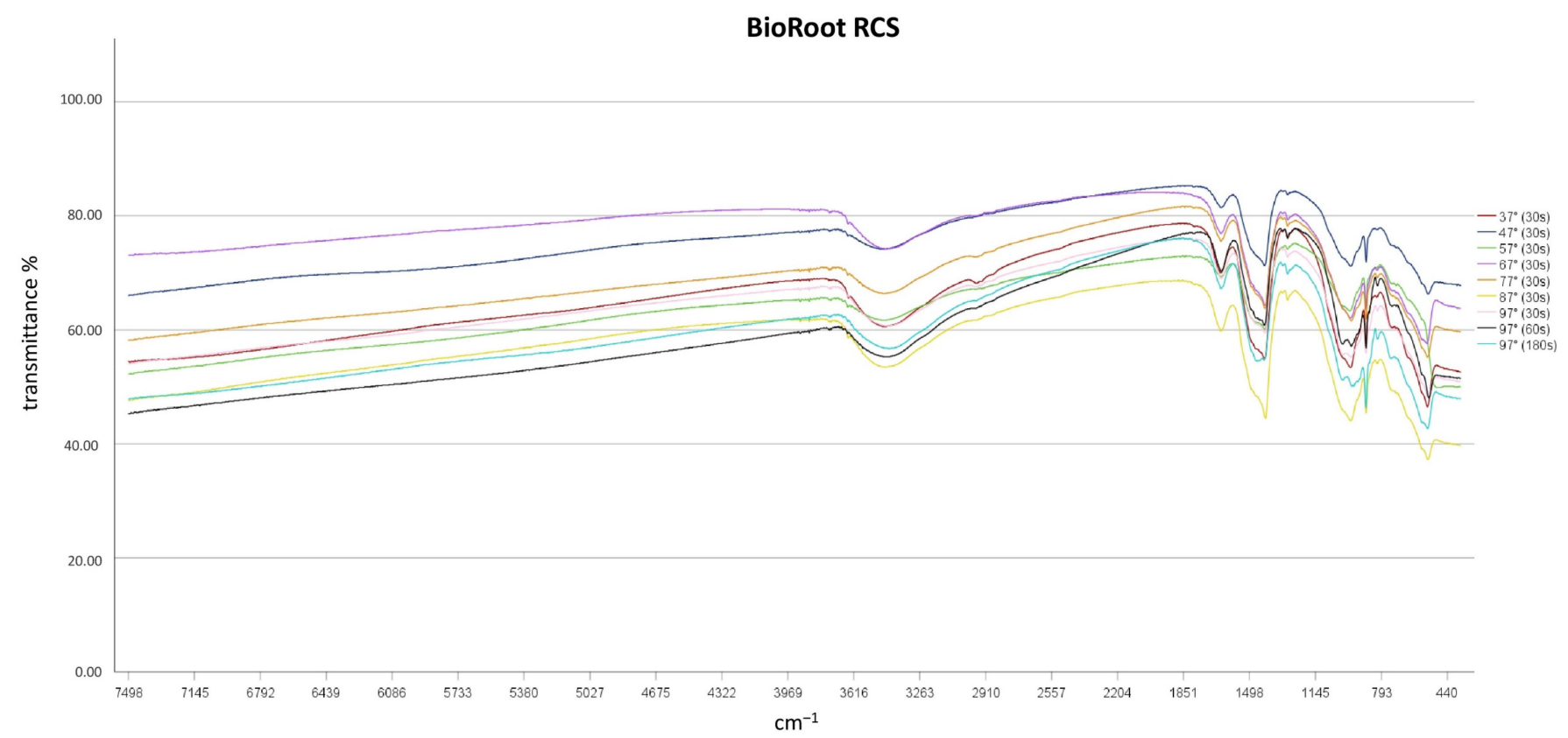

Figure 4. FT-IR spectroscopic plots of BioRoot RCS.

\section{Discussion}

The effect of heat on calcium silicate-based sealers was evaluated at different temperatures. The experimental setup regarding temperature levels and heating times was based on recently reported clinically relevant values $[7,17]$, supplemented by a range of temperatures that could occur. BR was found to set when heated above $77^{\circ} \mathrm{C}$, while heating did not compromise the physical properties of TFBC and TFHF. However, the chemical structures of the calcium silicate-based sealers tested were not negatively affected. Therefore, the null hypothesis was partly accepted. 
As already presented in a preliminary study [10], applying clinically relevant heating intervals and maximum temperatures are prerequisites when investigating the effect of heat on endodontic sealers under laboratory conditions. Mimicking the in vivo temperature dissipation, intracanal temperatures ranging below $60^{\circ} \mathrm{C}$ during warm vertical compaction approaches were found [17]. The use of carrier-based warm obturation techniques resulted in even lower intracanal temperature rises affecting the sealer with temperatures of less than $10^{\circ} \mathrm{C}$ [17]. These facts were taken into consideration in the present study in order to generate clinically relevant results about thermal treatment of root canal sealers. Therefore, sealers were heated over short clinically relevant periods in closed containers and cooled down to body temperature immediately afterwards. In addition, temperature levels were chosen according to clinically based considerations $[10,17]$. To investigate the physical properties of sealers, assessments according to the ISO specification 6876 are well established [25]. Assessment of chemical changes in sealers after thermal treatment by means of FT-IR spectroscopy presents a well-established methodology $[10,14]$. To investigate the long-term effect of thermal treatment on calcium silicate-based sealers, specimens were stored for 8 weeks. Calcium silicate-based materials have a prolonged setting reaction [16] and, especially in the case of premixed sealer formulations, communicate with the environment to incorporate surrounding water during the setting reaction [26]. Therefore, further to the short-term effect of heat on possible destruction of the chemical composition the long-term effect of heat on the setting profile is of scientific interest.

Originally, calcium silicate-based sealers were designed for cold obturation techniques [1]. As a growing demand was postulated by clinicians to combine the advantageous properties of calcium silicate-based sealers [4] with three-dimensional obturation of the root canal space using thermo-plasticized gutta-percha, Total Fill BC Sealer HiFlow was especially designed for this purpose. While the effect of heat on this sealer and partly on other calcium silicate-based sealers has already been addressed $[11,13,14]$, the so obtained results might not allow a general recommendation for the clinician as to which sealer can be safely used in combination with a certain warm root canal filling technique. Different temperature levels relying on the heat carrier's device display [11] or general observations of the heat carrier tip temperature [14] were investigated. Recently, the factual heat carrier's tip temperature was shown to remain under the displayed temperature levels [27] and, due to temperature dissipation, the intracanal sealer temperature is generally lower than the heat carrier's temperature [17]. To address the outcome of clinical orientated thermal processing, a range of temperature was chosen [10]. In addition, the long-term effect of thermal processing on the setting reaction was addressed, as studies so far only assessed the effect of heat within the moment of thermal treatment [12] or after the primary setting reaction $[11,13]$. As prolonged hydration and structure maturation of calcium silicate-based materials have been reported [16], the effect of thermal treatment on the final constitution of the sealers has remained unknown so far.

The sealers investigated in this study showed different behavior after thermal processing. While no relevant changes of the physical properties were found with either TFBC or TFHF, BR fully set after exposure to temperatures of $87^{\circ} \mathrm{C}$ and above. In compliance with previously published results $[11,13,14]$, thermal treatment did not affect premixed calcium silicate-based sealer composition. Though TFHF exhibited higher flow and higher setting time at all temperature levels, flow, and setting time both of TFHF and TFBC did not descend under clinically relevant thresholds. Film thickness of TFHF and TFBC appeared equal and was not influenced by temperature (Tables 3 and 4). Other than the premixed formulation, $\mathrm{BR}$ was affected in its physical properties by thermal treatment. Beginning with a temperature of $87^{\circ} \mathrm{C}$, the sealer appeared set and assessment of its physical properties was impossible (Table 2). Aksel et al. [11] also reported a lower viscosity of BR after thermal treatment supporting the presents results with regard of the differences in the heating process. Up to a temperature of $77^{\circ} \mathrm{C}$, physical properties of $\mathrm{BR}$ remained above clinically relevant minimum thresholds (Table 2). A possible explanation for the different behavior of two-component and ready-to-use formulations is the momentum of water 
uptake and the beginning of the setting reaction. BR is mixed with water and thermal treatment can either lead to evaporation of the water, resulting in a solid form of the sealer or to accelerated reaction kinematics enhancing the primary setting reaction of BR. Weight loss of BR was reported after thermal treatment, indicating evaporation of the contained water [11]. As TFBC and TFHF do not contain water in their premixed formulation no such effects are possible. Water uptake from surrounding structures clinically happens after the thermal process and this aspect was taken into consideration in the present study insofar as the specimens were stored in a humid environment. As both TFBC and TFHF showed no differences in setting time after the thermal treatment, the primary composition of both materials seems to be inert to thermal treatment. Thermal treatment meanwhile showed no relevant impact on the chemical composition of long-term incubated calcium silicatebased sealers. The primary composition of all sealers was inert to temperature, and water uptake in the following weeks was enough to allow a full setting reaction of the materials. TFBC and TFHF showed similar composition while the FTIR spectra of BR were different indicating a difference in the composition of premixed sealers and two-component sealers.

Water was present at all temperature levels in all specimens representing the hydration reaction of calcium silicates, which took place even after thermal treatment either from incorporated water or external sources in the humid environment. No characteristic $\mathrm{Ca}(\mathrm{OH})_{2}$ bands $\left(\mathrm{O}-\mathrm{H}\right.$ stretch at $\left.3646 \mathrm{~cm}^{-1}\right)$ were detected in TFHF and TFBC, while a small peak occurred in BR samples in this region [20]. After the prolonged storage, the formation of carbonates from calcium hydroxide with atmospheric $\mathrm{CO}_{2}$ is likely [28] as characteristic bands could be detected at 879 and from 1400 to $1500 \mathrm{~cm}^{-1}$ in all specimens [21,22]. Organic structures were detected in both premixed sealer formulations while not being present in BR. This finding may be due to the thickening agents or fillers used in premixed formulation to fabricate a clinically applicable sealer from a powder formulation. No such molecules must be incorporated into BR, as this sealer is mixed from powder and liquid prior to clinical application.

According to the present results and within the limitations of a laboratory simulation of thermal treatment, premixed calcium silicate-based sealer formulations can be regarded as safe for warm root canal filling techniques. The use of BR is limited to cold lateral compaction or single cone root canal filling and maybe carrier-based warm root canal filling, as these low-temperature techniques have been shown to only increase the sealer temperature to a very limited extent [17]. Still, further research is necessary to give a general recommendation about carrier-based systems.

\section{Conclusions}

Within the limitations of the study, it can be concluded that (i) thermal treatment simulating clinically relevant temperature levels and heating times does not result in relevant physical or chemical alterations to TFBC and TFHF at all temperature levels, (ii) no chemical changes can be observed with BR, and (iii) BR set immediately when heated above $77^{\circ} \mathrm{C}$ for $30 \mathrm{~s}$. Therefore, TFBC and TFHF can be considered suitable for warm obturation techniques, while BR should only be implemented with cold obturation techniques.

Author Contributions: Conceptualization: D.D., E.S. and S.B., methodology: D.D., M.I. and S.B., investigation: D.D., M.I., M.P.R. and I.W., resources: E.S., data curation: E.S., writing-Original draft preparation: D.D., writing—Review and editing: E.S., visualization: D.D., supervision: E.S. All authors have read and agreed to the published version of the manuscript.

Funding: This research received no external funding.

Data Availability Statement: The data presented in this study are available on request from the corresponding author.

Conflicts of Interest: The authors deny any conflict of interest. 


\section{References}

1. Donnermeyer, D.; Bürklein, S.; Dammaschke, T.; Schäfer, E. Endodontic sealers based on calcium silicates: A systematic review. Odontology 2019, 107, 421-436. [CrossRef]

2. Harms, C.S.; Schäfer, E.; Dammaschke, T. Clinical evaluation of direct pulp capping using a calcium silicate cement-treatment outcomes over an average period of 2.3 years. Clin. Oral. Investig. 2019, 23, 3491-3499. [CrossRef] [PubMed]

3. Donfrancesco, O.; Seracchiani, M.; Morese, A.; Ferri, V.; Nottola, S.A.; Relucenti, M.; Gambarini, G.; Testarelli, L. Analysis of Stability in Time of Marginal Adaptation of Endosequence Root Repair Material on Biological Samples. Dent. Hypotheses 2020, 11, 11-15.

4. Donnermeyer, D.; Dammaschke, T.; Schäfer, E. Endodontics in the era of hydraulic materials. Hydraulic calcium silicate-based sealers-A game changer in root canal obturation? ENDO Endod. Pract. Today 2020, 4, 197-203.

5. Schilder, H. Filling root canals in three dimensions. J. Endod. 1967, 32, 281-290. [CrossRef]

6. Schäfer, E.; Köster, M.; Bürklein, S. Percentage of gutta-percha-filled areas in canals instrumented with nickel-titanium systems and obturated with matching single cones. J. Endod. 2013, 39, 924-928. [CrossRef] [PubMed]

7. Buchanan, L.S. Filling root canal systems with centered condensation: Concepts, instruments, and techniques. Dent. Today 2004, 23, 102-106.

8. Ørstavik, D. Materials used for root canal obturation: Technical, biological and clinical testing. Endod. Top. 2005, 12, 25-38. [CrossRef]

9. Rodríguez-Lozano, F.J.; López-García, S.; García-Bernal, D.; Tomás-Catalá, C.J.; Santos, J.M.; Llena, C.; Lozano, A.; Murcia, L.; Forner, L. Chemical composition and bioactivity potential of the new Endosequence BC sealer formulation HiFlow. Int. Endod. J. 2020, 53, 1216-1228. [CrossRef] [PubMed]

10. Donnermeyer, D.; Urban, K.; Bürklein, S.; Schäfer, E. Physico-chemical investigation of endodontic sealers exposed to simulated intracanal heat application: Epoxy resins and zinc oxide-eugenols. Int. Endod. J. 2020, 53, 690-697. [CrossRef]

11. Aksel, H.; Makowka, S.; Bosaid, F.; Guardian, M.G.; Sarkar, D.; Azim, A.A. Effect of heat application on the physical properties and chemical structure of calcium silicate-based sealers. Clin. Oral Investig. 2020. [CrossRef]

12. Atmeh, A.R.; Hadis, M.; Camilleri, J. Real-time chemical analysis of root filling materials with heating: Guideline for safe temperature levels. Int. Endod. J. 2020, 53, 698-708. [CrossRef]

13. Chen, B.; Haapasalo, M.; Mobuchon, C.; Li, X.; Ma, J.; Shen, Y. Cytotoxicity and the Effect of Temperature on Physical Properties and Chemical Composition of a New Calcium Silicate-based Root Canal Sealer. J. Endod. 2020, 46, 531-538. [CrossRef] [PubMed]

14. Hadis, M.; Camilleri, J. Characterization of heat resistant hydraulic sealer for warm vertical obturation. Dent. Mater. 2020, 36, 1183-1189. [CrossRef] [PubMed]

15. Yamauchi, S.; Watanabe, S.; Okiji, T. Effects of heating on the physical properties of premixed calcium silicate-based root canal sealers. J. Oral Sci. 2020, 63, 65-69. [CrossRef]

16. Chedella, S.C.V.; Berzins, D.W. A differential scanning calorimetry study of the setting reaction of MTA. Int. Endod. J. 2020, 43, 509-518. [CrossRef]

17. Donnermeyer, D. , Schäfer, E.; Bürklein, S. Real-time intracanal temperature measurement during different obturation techniques. J. Endod. 2018, 44, 1832-1836. [CrossRef]

18. Atmeh, A.; AlShwaimi, E. The effect of heating time and temperature on epoxy resin and calcium silicate-based endodontic sealers. J. Endod. 2017, 43, 2112-2118. [CrossRef] [PubMed]

19. International Organization for Standardization. International Standard ISO 6876: Dentistry—Root Canal Sealing Materials; International Organization for Standardization: Geneva, Switzerland, 2012.

20. Mollah, M.Y.A.; Yu, W.; Schennach, R.; Cocke, D.L. A Fourier transform infrared spectroscopic investigation of the early hydration of Portland cement and the influence of sodium lignosulfonate. Cem. Concr. Res. 2000, 30, 267-273. [CrossRef]

21. Ylmén, R.; Jäglid, U.; Steenari, B.; Panas, I. Early hydration and setting of Portland cement monitored by IR, SEM and Vicat techniques. Cem. Concr. Res. 2009, 39, 433-439. [CrossRef]

22. Wang, P.; Li, C.; Gong, H.; Jiang, X.; Wang, H.; Li, K. Effects of synthesis conditions on the morphology of hydroxyapatite nanoparticles produced by wet chemical process. Powder Technol. 2010, 203, 315-321. [CrossRef]

23. Maeda, Y.; Nakamura, T.; Ikeda, I. Changes in the hydration starts of Poly(N-n-propylmethacrylamide) and Poly(Nisopropylmethacrylamide) during their phase transition in water observed by FTIR spectroscopy. Macromolecules 2001, 34, 8246-8251. [CrossRef]

24. Chérgoles Asensio, R.; San Andrés Moya, M.; de la Roja, J.M.; Gómez, M. Analytiacal characterization of polymers used in conservation and restoration by ATR-FTIR sprectroscopy. Anal. Bioanal. Chem. 2009, 395, 2081-2096. [CrossRef]

25. Zhou, H.M.; Shen, Y.; Zheng, W.; Li, L.; Zheng, Y.F.; Haapasalo, M. Physical properties of 5 root canal sealers. J. Endod. 2013, 39, 1281-1286. [CrossRef] [PubMed]

26. Kebudi Benezra, M.; Schembri Wismayer, P.; Camilleri, J. Influence of environment on testing of hydraulic sealers. Sci. Rep. 2017, 7, 17927. [CrossRef]

27. Viapiana, R.; Baluci, C.A.; Tanomaru-Filho, M.; Camilleri, J. Investigation of chemical changes in sealers during application of the warm vertical compaction technique. Int. Endod. J. 2015, 48, 16-27. [CrossRef] [PubMed]

28. Zhan, B.J.; Xuan, D.X.; Poon, C.S.; Shi, S.J.; Kou, S.C. Characterization of C-S-H formed in coupled $\mathrm{CO}_{2}$-water cured Portland cement pastes. Mater. Struct. 2018, 51, 92. [CrossRef] 